\title{
Where is the Source of Unconformity-related Uranium Deposits? Insight from Reactive Mass Transport Modelling
}

\author{
${ }^{1}$ School of the Environment \\ University of Windsor \\ Windsor, Ontario, Canada \\ Email: jianweny@uwindsor.ca \\ Unconformity-related uranium (URU) deposits \\ constitute approximately $35 \%$ of the Earth's proven \\ uranium reserves. However, the question of where the \\ large amount of uranium is sourced remains \\ unresolved. To address this issue, a highly \\ conceptualized 2-D model was developed with \\ consideration of graphite-rich fault zone(s) as a \\ reducing agent. A series of reactive mass transport \\ modelling were carried out using TOUGHREACT by \\ assigning aqueous uranium sources to different \\ locations in the solution domain, indicating that the \\ source of giant URU deposits originated more likely \\ from the basinal sediments rather than from the \\ basement rocks.
}

